\title{
Oxidative leaching process with cupric ion in hydrochloric acid media for recovery of Pd and Rh from spent catalytic converters
}

\author{
C.A. Nogueira ${ }^{a}, *$, A.P. Paiva ${ }^{b}$, P.C. Oliveira ${ }^{a}$, M.C. Costa $^{c}$, A.M. Rosa da Costa ${ }^{d}$ \\ a Laboratório Nacional de Energia e Geologia, I.P., Campus do Lumiar, 1649-038 Lisboa, Portugal \\ b Centro de Química e Bioquímica, Departamento de Química e Bioquímica, Faculdade de Ciências da Universidade de Lisboa, 1749-016 Lisboa, Portugal \\ ' Centro de Ciências do Mar, Departamento de Química e Farmácia, Faculdade de Ciências e de Tecnologia, Campus de Gambelas, 8005-139 Faro, Portugal \\ d Centro de Investigação em Química do Algarve, Departamento de Química e Farmácia, Faculdade de Ciências e de Tecnologia, Campus de Gambelas, \\ 8005-139 Faro, Portugal
}

\section{H I G H L I G H T S}

- A new leaching process based on $\mathrm{Cu}^{2+} / \mathrm{HCl}$ media for recovering Pd and $\mathrm{Rh}$ from spent autocatalytic converters is presented.

- Palladium and rhodium were efficiently leached, with attained maximum yields of $95 \%$ and $86 \%$, respectively.

- Temperature, time, and $\mathrm{HCl}$ and $\mathrm{Cu}^{2+}$ concentrations were found to be significant factors in the leaching of Pd and Rh.

\section{A R T I C L E I N F O}

\section{Article history:}

Received 17 February 2014

Received in revised form 14 May 2014

Accepted 31 May 2014

Available online 7 June 2014

\section{Keywords:}

Recycling

Pd-Rh catalyst

Hydrometallurgy

Oxidative leaching

Cupric chloride

\begin{abstract}
A B S T R A C T
The recycling of platinum-group metals from wastes such as autocatalytic converters is getting growing attention due to the scarcity of these precious metals and the market pressure originated by increase of demand in current and emerging applications. Hydrometallurgical treatment of such wastes is an alternative way to the most usual pyrometallurgical processes based on smelter operations. This paper focuses on the development of a leaching process using cupric chloride as oxidising agent, in $\mathrm{HCl}$ media, for recovery of palladium and rhodium from a spent catalyst. The chloride media allows the adequate conditions for oxidising and solubilising the metals, as demonstrated by equilibrium calculations based on thermodynamic data. The experimental study of the leaching process revealed that Pd solubilisation is clearly easier than that of $\mathrm{Rh}$. The factors temperature, time, and $\mathrm{HCl}$ and $\mathrm{Cu}^{2+}$ concentrations were significant regarding Pd and Rh leaching, the latter requiring higher factor values to achieve the same results. Leaching yields of $95 \% \mathrm{Pd}$ and $86 \% \mathrm{Rh}$ were achieved under optimised conditions $\left(T=80^{\circ} \mathrm{C}, t=4 \mathrm{~h}\right.$, $\left.[\mathrm{HCl}]=6 \mathrm{M},\left[\mathrm{Cu}^{2+}\right]=0.3 \mathrm{M}\right)$.
\end{abstract}

(C) 2014 Elsevier B.V. All rights reserved.

\section{Introduction}

Autocatalytic converters are the main application of platinumgroup metals (PGM's), representing more than 50\% of PGM's market [1]. Utilisation of such type of catalysts is being generalised worldwide due to the growing concern related with gas emissions and the subsequent potential environment damage.

Platinum, palladium and rhodium are the three metals used in autocatalyst manufacturing. Pt and Pt/Rh were the PGM's initially used in primary autocatalytic converters, but later (since the

\footnotetext{
* Corresponding author. Tel.: +351 210924654.

E-mail addresses: carlos.nogueira@lneg.pt (C.A. Nogueira), appaiva@fc.ul.pt (A.P. Paiva), mcorada@ualg.pt (M.C. Costa), amcosta@ualg.pt (A.M.R. da Costa).

90s), mixtures of $\mathrm{Pd} / \mathrm{Rh}$ were progressively introduced as unleaded fuel was being generalised, and engines were becoming more efficient and cleaner [2]. Nowadays, catalysts based in Pd only can be frequently found in the market.

Considered critical metals, PGM's are scarce and the growing demand will lead to a substantial increase in pressure on their market $[3,4]$. Consequently, all possible sources of PGM's shall not be neglected, and residues such as spent catalysts are considered as important secondary resources in this context.

Besides the economic relevance, end-of life catalytic converters should be correctly managed to avoid environmental and health risks associated with the presence of hazardous substances such as submicron fine particles [5] containing heavy metals and unburned hydrocarbons or their combustion products. In terms of management hierarchy, regeneration, reactivation and reuse would be 